\title{
Teacher responses to their multiple goals for teaching energy
}

\author{
Michael C. Wittmann, ${ }^{1,2}$ Carolina Alvarado, ${ }^{2}$ and Laura Millay ${ }^{2}$ \\ ${ }^{1}$ University of Maine, Department of Physics and Astronomy \\ 5709 Bennett Hall, Orono, ME, 04469-5709 \\ ${ }^{2}$ University of Maine, Center for Research in STEM Education \\ 5727 Estabrooke Hall, Orono, ME, 04469-5727
}

\begin{abstract}
Teachers discussing pedagogical strategies to help students with an incorrect idea about potential energy expressed competing goals for guiding student thinking: keep it simple and explore complexity. On the one hand, teachers wished to avoid being "overly complicated" in their teaching, suggesting that they should have students stick to naming forms of energy in a system and naming principles like the law of conservation of energy. On the other hand, teachers recognized that students might also engage with, wonder about, and have good ideas about systems, mechanisms, and causality. In addition, teachers themselves showed a need develop operational understandings of energy transformation, conservation, and system even in a simple energy scenario, rather than simply identifying forms and principles. Thus, the initial desire for keeping instruction simple was contradicted both by the recognition that students were capable of more complex analysis, even if it interfered with the goals of simple instruction, and by an awareness that understanding even a simple energy scenario involves grappling with complex ideas.
\end{abstract}

PACS: 1.40.ek, 01.40.Fk, 01.40.J, 01.40.jh

\section{INTRODUCTION}

The teaching and learning of energy have gained new prominence in the Next Generation Science Standards [1], where energy is both a core idea in the life, earth, and physical sciences and energy flow and conservation are crosscutting concepts important to all the sciences. In the Maine Physical Sciences Partnership (MainePSP, NSF MSP-0962805), we have collaborated with teachers on professional development around content knowledge, knowledge of student ideas, and development of pedagogical strategies to best address student needs. Our work is strongly influenced by Deborah Ball and collaborators' discussion of Mathematical Knowledge for Teaching [2] as well as the professional development of Cognitively Guided Instruction [3]. We hope to help teachers become more responsive in the classroom by focusing on the disciplinary substance of student ideas [4].

\section{DISCUSSING STUDENT IDEAS}

As part of a student survey given before and after instruction in eighth-grade classrooms, we asked the question shown in Figure 1. This question was developed as part of our MainePSP study to evaluate the changes in student understanding based on targeted instruction on energy. Data from this question have been gathered in multiple years, with nearly 4,000 student responses collected from 2010 to 2015.

Separately from the students, teachers answered the survey. They were further asked to predict a typical (incorrect) student response. We provided them with a typical incorrect student response from before instruction, namely the idea that there is "no energy" in picture 1 and only "kinetic energy" in picture 2 of Fig. 1. Most teachers predicted that this would be most common incorrect student response before we provided it to them, but we wanted to be sure that all teachers responded to the next activity with the same information. We then asked teachers how they would respond if a student in their class gave this answer. We collected several years of responses.

During an evening professional development meeting of the MainePSP in 2014, we shared four anonymized teacher responses to the question of how to address a typical incorrect student response. Table 1 provides two of the responses discussed that evening - the other two were also discussed but are not part of the episode described below. We asked the teachers working in smaller groups to discuss what they noticed about the written responses. The goal of this part of the professional development session was to prompt discussion about pedagogical interventions for working with student thinking around a specific (but generalizable) energy scenario. We wanted to get the teachers thinking about

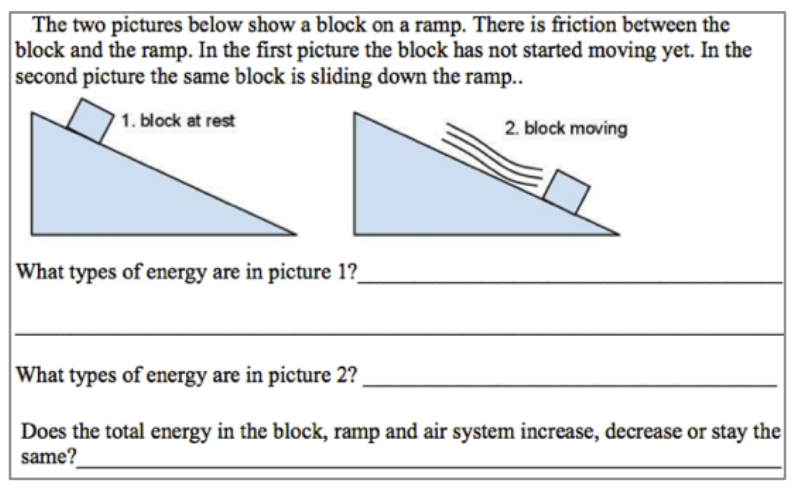

FIG 1. Open ended set of questions in the Student Energy Survey, as shown in the Teacher Energy Survey. 
TABLE 1. Teacher written responses that were analyzed during the cohort meeting.

\begin{tabular}{l|l}
\hline ID & $\begin{array}{l}\text { "There is no energy in picture 1..." - If a student answered this way in your class, describe with as much detail } \\
\text { as possible what you would do. Please explain your reasoning. }\end{array}$ \\
\hline 1 & $\begin{array}{l}\text { I would begin by offering the scientific definition of energy, then introduce the concept of potential energy by } \\
\text { stretching rubber bands and then firing them off, holding objects in the air and then releasing them, etc. I would } \\
\text { then explain how any kinetic energy, the energy of motion, has to result from the presence of potential energy } \\
\text { to begin with. If you have no energy to start, you have nothing to work with in order to create motion. The } \\
\text { maximum kinetic energy you can achieve is determined by the amount of potential energy you had in the first } \\
\text { place. Therefore you don't create energy when motion begins, but you've begun to transform that pre-existing } \\
\text { potential energy into kinetic energy, but at no time is energy being created or destroyed, just changed. }\end{array}$ \\
\hline 2 & $\begin{array}{l}\text { I would ask them where the energy went, when the block stopped moving at the end of the ramp. Remind them } \\
\text { about the energy transfers and introduce the law of conservation of energy. / I would provide them with other } \\
\text { examples so they could transfer the knowledge to other situations. Also, demonstrate the situation because they } \\
\text { retain information by doing the activity. }\end{array}$ \\
\hline
\end{tabular}

different pedagogical options and we thought the discussion of pedagogical strategies and student thinking would give us insight into how teachers used their understandings of energy content to guide their instructional choices. However, we heard little talk about specific pedagogical interventions and instead found evidence of tensions in teachers' ideas about how to work with student thinking, in particular a tension between on the one hand seeking to promote simple ways for students to think about energy forms and principles while on the other hand recognizing and seeking to explore the complex ideas needed to understand energy transfer, transformation, and conservation.

\section{DATA COLLECTION}

Data were gathered by audio- and videotaping all 13 teachers taking part in this part of the professional development. Two video cameras were placed to capture the entire room. We planned to use at least one audio recorder per group of 2 or 3 teachers, but one group of 6 formed as smaller groups combined. This group was captured on 2 audio recorders.

From our participation in the activity, we observed that the group of 6 engaged in the most active and rich conversation on the task. Of the other groups, one involved newcomers unfamiliar with past work in the MainePSP, one was consistently discussing other topics, and one had a rich conversation but was guided heavily by a graduate student researcher who was part of the group. We chose the group of 6 for detailed analysis.

\section{FINDINGS: SIMPLICITY, STUDENTS, AND SENSEMAKING}

To illustrate the tension between teachers' desires for simplicity and complexity, we give a detailed description of teachers discussing what they noticed in their colleagues' written descriptions of proposed pedagogical interventions. Because we are analyzing the group as a whole, we leave out details of the individual teacher names. Four broad themes emerged in their responses.

\section{A. Wishing to avoid being "Overly complicated"}

At the start of the discussion, multiple teachers expressed a desire to keep instruction simple. One teacher critiqued response 2 (see Table 1) "because it starts with the ending. Like, they talk about when the box stops at the bottom of the ramp. Well, we are talking about the box sitting at the top of the ramp." Another responded, "you don't want to get overly complicated." The first said, "Address the actual thing!" The second teacher outlined the important ideas, "Yeah. The only thing we are trying to do is Law of Conservation of Energy, potential energy, kinetic energy, and friction. Anything more than that, that's - let them master this first, you know what I mean?" This focus on a universal law, forms of energy, and the role of friction was affirmed by many others in the group. We return to the issue of whether to consider the box at the bottom, and how it is related energy of the box at the top, in another part of the teacher discussion, discussed below.

This conversation was immediately followed by teacher criticism of the last sentence of response 2, "demonstrate the situation because they retain information by doing the activity." One teacher said, with a dismissive tone, "So you put a block in a ramp?" adding, "Now look at that block!" and gesturing as if standing back and watching something that wasn't moving. Others joined in this critique: a simple demonstration was seemingly too simple.

\section{B. Wishing to honor good student ideas}

While seeking simplicity, teachers also showed evidence of wanting to honor student ideas. One teacher pointed out, "One of the difficulties of teaching physics is that it can get so philosophical." In particular, students might "bring in" ideas "that might be true." This was a problem if you wanted "to keep focused," but you "couldn't say no to them, because they're right, you know?" In these statements (shared among several teachers) we note the respect of teachers for their students' abilities to bring in ideas that might distract the class but could also contribute to learning in the classroom. 
We also learn more about teachers' goals about teaching. Not only is there a desire not to be "overly complicated," but as a teacher one has to "keep focused." This is placed in contrast to the idea of letting students "bring in" other ideas, though valuing those where "they're right." A teacher summarized the dilemma by saying, "Trying to keep the concept simple and concise is not always easy." Another conveyed the problem that might occur, stating, "it can become a conversation of "Why? but why? but why? Where did the energy come from there? but where did it come before that? or where did it come...?!"'

The tension between simplicity and honoring ideas played out in an interesting way in the teachers' own discussions of the physics.

\section{Teacher as sensemakers}

Though teachers advocated for keeping things simple and not overly complicated, when acting as learners, they did not stick to the simple description of forms and laws.

\section{Inquiring into causality and mechanism}

A teacher raised the question "how does this start going down?" One of the previously dismissive teachers added, "Right - what starts the movement?" This question of mechanism became a dominant one for the teachers. Rather than listing laws (such as conservation) and forms, the teachers began asking deeper questions about the content, including making specific pedagogical recommendations.

For example, a teacher immediately stated, "a ball would be better." This pedagogical suggestion might help avoid some of the issue, in that balls naturally roll on an incline, while blocks might not, depending on the friction. One teacher asked, "Did [the block] just automatically start moving with no apparent reason?"

Teachers proposed multiple reasons. Some spoke of forces, with a teacher wondering "if you are adding a force to it" and another asking, "What happened to the friction? The friction just disappeared?" Others spoke in terms of energy, asking, "if we are talking about conservation of energy, where is this extra invisible energy?" For this teacher, a conserved amount of energy, with observable energy (e.g. from motion) at the end, suggested an "invisible energy" rather than "no energy."

\section{Describing energy mechanisms, briefly}

After a brief discussion of other topics, teachers returned to the question of both energy and mechanism, focusing on response 1 in Table 1 . One teacher said, "I do like the sentence, 'the maximum KE you can achieve is determined by the amount of potential energy you had in the first place,' I think that's good." In stating that there is a kinetic energy later on, determined by the potential energy at the start, teachers were using the idea of conservation operationally, rather than simply naming it as a principle. They were also assuming that the one kind of energy transforms into the other. This attention to energy shows the complexity involved in modeling the situation using energy, in particular that one has to think about the box at the bottom of the ramp in order to think about it at the top of the ramp.

Further, teachers began to ascribe causal elements to energy, in that it helps create motion. The teacher who earlier spoke of "invisible energy" said, "I did like also the sentence, 'if you have no energy to start, you have nothing to work with in order to create motion.' Well, that's true!" and added, "So, there is no energy involved with the block sitting there, how does it have any motion to begin with? So I did like that." This argument suggests that having energy creates motion, and that observations of a system later in its evolution can help us understand its properties earlier in time. These are important and essential ideas for using energy to describe a system.

Teachers did not stick to this explanation, though. The teachers revisited several of the previously described ideas in the conversation that followed. There were comments about the demo ("the demo - the demo thing is just, really?"), the reason the block started moving ("how did that damn block get down the ramp?"), and forces ("I think it just, you know, over time, gets out of friction.") A teacher brought back the idea of added effort, saying the box "was up there, it was kind of creaking, it was really trying... to get started, and all it needed it was a little bit more stick to it until [it began moving]." This description contradicts both the forces-based argument and the energy-based argument by focusing on the efforts of the box. Teachers did not follow up on this, other than to continue asking, "so how does it overcome that [the block is at rest]?"

\section{Using silliness to convey important ideas}

In addition to the many moments of laughter as teachers worked through each other's ideas, there were three moments of teachers inventing less-than-serious models that nevertheless contained meaningful hints about the physics. In the first, an unseen magnet held the (seemingly) metal block in place and was removed, allowing it to slide. Later, a teacher suggested a gust of wind blew it down the ramp. Both suggestions contained ideas about adding or removing a force, though they were offered and taken up in jest.

At a different moment, a teacher said "the sun! It's always the sun!" This brought a barrage of laughing comments, as teachers in a jumble of voices said, "That's how the block moved initially. It was sitting in the sun absorbing energy, until it got enough." To general laughter, they said, "It wasn't a magnet, it was frozen! And then the sun got it out." This mechanism is more connected to energy than a force, though not formally expressed as such.

Silly as these moments were for the teachers, they highlight that the teachers were making sense of the situation and not thinking as much about pedagogy. Their ideas spoke of energy as well as forces. In the case of the 
sun warming the block, they raised the idea of energy being put into the system in some fashion to allow the block to have the energy to move. For all the joking, that principle was correct (e.g., a hand would have had to lift the block to its original height, also adding energy to the system).

\section{DISCUSSION}

In this 12-minute episode, teachers spent their time on making sense of the physics of the survey responses, asking their own questions about the physics, and providing insights into their attitudes toward students. They conveyed several messages about the teaching and learning of energy. Some were explicit, while others were implicit in the way they themselves talked about the content.

Teachers had multiple perspectives on student learning. They advocated keeping instruction simple and not "overly complicated," giving reasons such as staying focused and not letting too many "why" questions get in the way of teaching that day's lesson. Based on previous conversations with these and other teachers, we believe they were aiming for the greatest number of students in their class to succeed. At the same time, teachers believed that students could be far more advanced, though their contributions might be disruptive to a class. The teachers' dilemma was between staying "simple and concise" and honoring creative ideas that arose in the classroom. We believe that this is a common problem for teachers, balancing between covering course material as simply as possible and honoring the creativity and knowledge of their students, even when it is more complex than what is expected.

In their own actions, teachers showed what sensemaking looked like. Teachers used multiple models when discussing the physics. They showed a consistent (and persistent) desire to understand the reasons for the box's initial motion. Their attention to the mechanism of the box's initial motion led to suggestions about pedagogy and several questions about the physics. On a formal level, they used both force- and energy-based models to make sense of a problematic situation. In seeking a mechanism and using multiple models to address their questions, they contradicted their desire for a simple, not "overly complicated" model of the situation.

While accounting for the box's initial motion, teachers also reversed themselves on which explanations were appropriate. At the beginning, a teacher had critically stated that the problem with response 2 was, "Because it starts with ending. Like, they talk about when the box stops at the bottom of the ramp. Well, we are talking about the box sitting at the top of the ramp." Later in the conversation, implicit talk about energy transformation and conservation, as well as recognizing the value of evaluating the system's

[1] Achieve Inc, (2013).

[2] D. L. Ball, M. H. Thames, and G. Phelps, J. Teach. Educ. 59, 389 (2008). time evolution, was shown to provide a richness of information that had not been part of the earlier discussion. Applying a systems analysis of energy provided a reason for the box's initial motion.

In addition to this formal work, they offered several ridiculous explanations (magnets, wind, the box's effort, and melting) to explain why the box might start moving. The teachers' laughter at the time of presenting these ideas suggested they were not being serious as they invented fantastic, silly models, but their ideas still contained kernels of the correct ideas in them. We note that teachers remembered these ideas even as a more serious analysis of the problem was discussed.

\section{CONCLUSIONS}

In this episode, teachers discussed pedagogy and grappled with content in ways that illustrated tensions between competing ideas about what kinds of student thinking to respond to. Should they keep it simple, promoting and working with assigning appropriate names to energy forms and principles? Or should they honor the complexity in thinking and wondering that students may bring to the classroom? The teachers' own persistent curiosity and the richness of their discussion about causality and mechanism in a simple energy scenario was inconsistent with their initial desire to keep these complex elements out of student instruction.

In our professional development, we use data gathered from teachers (or, in other settings, students) to foster conversation about content and pedagogy. By analyzing the comments of their colleagues, they explored important ideas about the content and the modeling of the physics, sought further knowledge about causality and mechanism, and discussed different pedagogical approaches to help make sense of the situation. The teachers' desires to keep instruction as simple as possible were inconsistent with their own curiosity to understand the situation, as well as their desire to honor students' ideas that went beyond what was asked in class. These results indicate a rich environment for discussing knowledge of content and students [2] as well as the disciplinary substance of the material [4].

\section{ACKNOWLEDGEMENTS}

We thank Alex Axthelm, Oai Ha, and Greg Kranich for their help with the manuscript. We also thank the teachers of the Maine Physical Sciences Partnership who participated in the activity. This work was supported in part by NSF grants MSP-0962805 and DRL-1222580.

[3] T. P. Carpenter, E. Fennema, P. L. Peterson, and D. A. Carey, J. Res. Math. Educ. 19, 385 (1988).

[4] J. E. Coffey, D. Hammer, D. M. Levin, and T. Grant, J. Res. Sci. Teach. 48, 1109 (2011). 